\title{
Horoscopes of the Moon: Weather Prediction as Astrology in Ptolemy's Tetrabiblos
}

\author{
Claire Hall | ORCID: 0000-0003-1351-1283 \\ All Souls College, University of Oxford, Oxford, UK \\ claire.hall@all-souls.ox.ac.uk
}

\begin{abstract}
Ptolemy's Tetrabiblos is not usually considered as a meteorological text. I examine the sections of the Tetrabiblos that deal with weather prediction and argue that Ptolemy considers it part of astrology. I show that the way Ptolemy categorises weather prediction differs significantly from other Greco-Roman writers, including Cicero (On Divination) and Sextus Empiricus (Against the Astrologers). I argue for these conclusions: first, that Ptolemy considers weather prediction to be part of astrology - i.e., a scientific practice which includes giving an account of the causes of phenomena with reference to the stars; to give such an account for the weather requires a practitioner to go beyond the observation and cataloguing of weather signs. Secondly, I argue that understanding weather prediction as astrology means that the distinction between horoscopic and general astrology is more fluid than is sometimes thought. Finally, I will show that Ptolemy's views on weather prediction provide a case study for his view of astral causation.
\end{abstract}

\section{Keywords}

Ptolemy - astrology - weather prediction - meteorology - signs - causes - Tetrabiblos Phases - astrometeorology - divination

\section{Introduction}

Ptolemy wrote about weather in several places in his work. His Phases, an almanac of weather signs for each day of each month, reads quite differently from his more widely read theoretical works like the Almagest or the Tetrabiblos. For 
the most part, the Phases is a highly conventional text, part of a tradition of weather calendars known as parapegmata which listed clear day-to-day signs and expectations for seasonal weather changes based on the passage of the stars through the night sky. ${ }^{1}$ A typical example, from the month of Athyr, which corresponds roughly to November, runs as follows:

6. 14 hours: the star on the knee of Sagittarius disappears. According to Conon and Eudoxus a bad mixture of winds. According to Callipus a bad mixture of airs. According to Caesar and Hipparchus south wind or cold north wind. ${ }^{2}$

In this, as in each entry in the Phases, Ptolemy lists a number of weather predictions from named authors, leaving the reader to choose between predictions. Where he doesn't name his sources, he makes reference instead by vague designations - including to a group he calls "the Egyptians." 3 While his sources are often in concordance, sometimes, as above, their predictions differ slightly in ways that are not always reconcilable. But a section at the end of the prologue to the Phases is different. The prologue begins conventionally, with a summary of what Ptolemy means by the phases of the stars, and a discussion of which regions he will discuss and what sorts of observational problems may be involved. But in the next, more theoretical section, Ptolemy puts forward an opinion which seems out of keeping with the rest of the work: "It is well to

1 While the term 'parapegma' can refer to just the text, many parapegmata, like modern calendars, are also physical objects with a way of marking off days (usually, in the Greek case, stone calendars with pegs). As Lehoux and others have shown, parapegmata have their own rhetorical structure and aims which are not always as obvious as they seem. Cf. Daryn Lehoux, Astronomy, Weather, and Calendars in the Ancient World: Parapegmata and Related Texts in Classical and Near Eastern Societies (Cambridge, 2007). For how parapegmata relate to other types of Greek calendar, see Sacha Stern, Calendars in Antiquity: Empires, States, and Societies (Oxford, 2012), ch. 1: "Calendars of Ancient Greece," 25-70. The most famous signs catalogue in the Greek world is Theophrastus, Theophrastus of Eresus: On Weather Signs, ed. David Sider and Carl Wolfram Brunschön (Leiden, 2007).

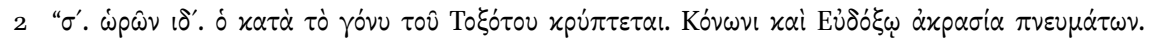

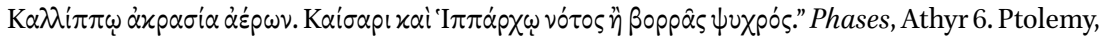
Phases in Claudii Ptolemaei opera quae exstant omnia. Vol. II. Opera Astronomica minora, ed. Johan Ludvig Heiberg (Leipzig, 1907), 21.17-22.2. Translation from Lehoux, Astronomy, 287.

3 For more on who these sources are, see Mark T. Riley, "Ptolemy's Use of His Predecessors' Data," Transactions of the American Philological Association, 125 (1995), 221-250; see also Gerd Graßhof, "The Babylonian Tradition of Celestial Phenomena and Ptolemy's Fixed Star Calendar," in Die Rolle der Astronomie in den Kulturen Mesopotamiens, ed. Hannes D. Galter (Graz, 1993), 95-137, for the possible Babylonian influence on Ptolemy. 
carry on the investigation of weather indications (and indeed of all such forecasting) with a clear idea first of all of the cause of such things."

While the rest of the Phases presents the evidence simply in the format of lists for the reader's consideration, here Ptolemy is caveating his own catalogue, arguing that a list of signs without a full explanation of the causes of weather phenomena cannot give the reader a full understanding. Instead, he suggests, one should think about other causes which could be at play in weather conditions, including planetary transits, the dates of the new and full moon, and the nature and qualities of the planets' configurations at the time. ${ }^{5}$ If the main body of the Phases offers only a conventional parapegma-style catalogue of weather signs, then what does Ptolemy mean by saying that we should take into consideration the moon, the sun, the effects of the planets and their aspects? And where - if not in the Phases - does he take these factors into consideration?

To answer these questions, I turn to another of Ptolemy's texts, the Tetrabiblos. Here, he offers a number of methods for predicting the weather using methods which do take into account the moon, the sun, and the planets and their aspects. While the Tetrabiblos is not usually taken as a meteorological text, it contains a great deal of material about weather and its prediction. ${ }^{6}$ By analysing these sections in detail, I make the following argument: Ptolemy did not object to catalogues of weather signs, as evidenced by his own Phases; however, for him, fully understanding the weather required understanding its causes. Understanding the causes of weather was therefore part of astrology the system by which human beings could understand the relationship between the movement of the heavens and events on earth. This view contrasts sharply with those of other Greco-Roman writers, who considered weather prediction

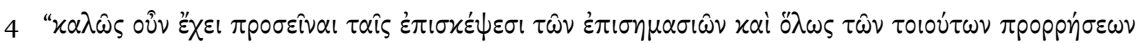

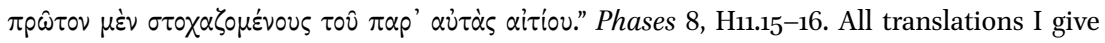
from the Phases are from Riley, "Ptolemy's Use," $243 \mathrm{ff}$.

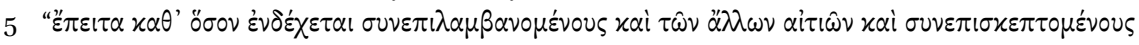

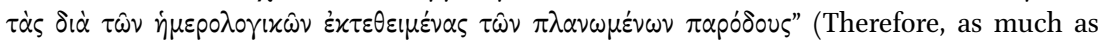
possible, we must take into account the other causative factors, and we must particularly examine the planetary transits as found in the almanacs). Phases 8, H11.24-27. The planets

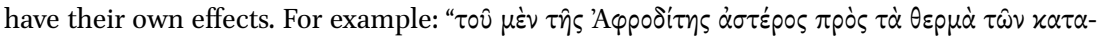

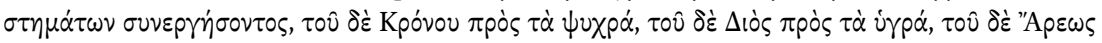

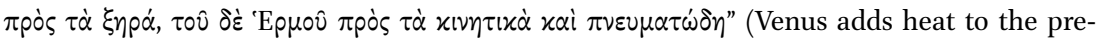
vailing conditions, Saturn cold, Jupiter moisture, Mars dryness, Mercury motion and wind). Phases 8, H12.6-10.

6 The table of contents in the Loeb edition of the Tetrabiblos does list a number of section titles about weather prediction; section titles may postdate Ptolemy; see Ptolemy, Tetrabiblos, ed. Frank E. Robbins, Loeb Classical Library 435 (Cambridge, MA, 1940). 
as a technique; as a type of uncontroversial technical skill that had similarities with divination but was nevertheless its own distinct category. I examine two other accounts of how weather prediction relates to astrology in Cicero's On Divination and Sextus Empiricus' Against the Astrologers.

Additionally, I argue that Ptolemy's understanding of weather as part of astrology shows that divisions drawn - both by Ptolemy and in scholarship between 'general' (or event-based) and 'horoscopic' (or individual natal) astrology are not strictly upheld. Although weather definitionally falls within the remit of 'general' astrology, the methods Ptolemy advocates for weather prediction include taking horoscopes of the moon and of eclipses, blurring the lines between the two types of prediction. Finally, I argue that Ptolemy uses the weather as a clear example of astral causation - both directly (the stars cause weather conditions) and indirectly (the stars cause regional weather which has an effect on human characteristics).

\section{Defining Weather}

Weather is connected to the heavens at a basic level by the relative positions of the earth and the stars and planets. ${ }^{7}$ In a heliocentric astronomical model, it is clear why seasonal weather depends on the astronomical arrangement of the earth: the tilt of the earth's axis, combined with our elliptical orbit around the sun, produces variation in temperature throughout the course of the year for different regions of the earth at different times. In the geocentric circularorbit model to which the majority of ancient Greco-Roman astronomers subscribed, a version this fact appears in a different form: the sun rises lower in the winter months; therefore, less direct heat is felt from it, and consequently, there is colder weather (although with a differential regional effect). ${ }^{8}$

Modern science understands weather phenomena, including rain and wind, to occur by means of self-contained processes within our atmosphere, such as

7 In what follows, I use 'astronomy' to mean the study of the arrangement and regular movement of the stars and planets. I use 'astrology' to mean prediction of effects on earth that derive from the movement of stars and planets. I use 'astrometeorology' to mean any kind of prediction of the weather by the stars. As will be clear from the latter two definitions, I consider astrometeorology to be a subtype of astrology; this a controversial claim and many scholars would restrict the use of the term 'astrology' to refer strictly to using the stars only to predict events in the lives of human beings.

8 See Alexander Jones, "Introduction," in Time and Cosmos in Greco-Roman Antiquity, ed. idem (Princeton, NJ, 2016), 19-44, 23ff. 
the water cycle or the atmospheric pressure system. ${ }^{9}$ Ancient meteorological writers also took this to be the case: Aristotle's Meteorology, for example, gives an accurate description of the water cycle and explains, among other things, why rainwater condenses high up mountains..$^{10}$ Nevertheless, there are quite substantial differences in how ancient and modern meteorological writers understand phenomena. Even if we leave aside the huge difference in equipment and scientific methods to gather and analyse data, there are some very basic differences in the categories Greco-Roman and modern scientific thinkers use to describe and account for phenomena, and their aims in doing so. One of the most basic is the division in contemporary science between the earth itself, the earth's atmosphere, and space. While ancient cosmologists did divide the heavens from the earth and its environs, following Aristotle it became a widespread standard to put the dividing line at the moon, dividing the universe into the 'celestial' sphere and the 'sublunary' sphere. ${ }^{11}$ Therefore, while modern meteorologists focus on phenomena within the earth's atmosphere (and not phenomena in the earth itself or in space), ancient meteorological writers after Aristotle tend to distinguish instead between celestial and sublunary phenomena. A consequence of this different taxonomy is that many of the 'sublunary' phenomena that ancient writers treat as weather, we would not consider as such: for example, ancient meteorological discussion often includes phenomena that we would consider astronomical events (such as comets) or geological events (such as earthquakes). However, Greco-Roman writers do also discuss many phenomena that fall, uncontroversially, under the heading of 'weather' in modern terms, including rains, storms, and winds. ${ }^{12}$

9 There are a few subtle features in the contemporary scientific picture: for example, changes in solar activity can lead to substantial changes in the weather on earth, and recent research has showed the effect of cosmic rays from supernovae on weather patterns; see Henrik Svensmark, Martin Andreas Enghoff, Nir Joseph Shaviv and Jacob Svensmark, "Increased Ionization Supports Growth of Aerosols into Cloud Condensation Nuclei," Nature Communications, 8 (2017), 2199.

10 Meteorologica I.350a. For more on Aristotle's Meteorology and its relationship to earlier works, see Monte Ransome Johnson, "Meteorology," in The Cambridge Companion to Greek and Roman Science, ed. Liba Taub (Cambridge, 2020), 160-184.

11 For Ptolemy's cosmology and its relationship to his astronomy and astrology, see Jacqueline Feke, Ptolemy's Philosophy: Mathematics as a Way of Life (Princeton, NJ, 2018), 168-200.

12 Lehoux, Astronomy, 5, distinguishes, for example, between 'earthly atmospheric' and 'celestial' phenomena in the Greek context. Michael Beardmore, "Ancient Weather Signs: Texts, Science and Tradition” (PhD diss., University of St Andrews, 2013), 8-11, argues instead that this distinction does not recognise those elements that take place at the boundary of the 'celestial', e.g., comets and shooting stars. In this, I agree with Beardmore. 
Greek does not have a single unified word for 'weather'. One of the most commonly used general terms is $\tau \dot{\alpha} \mu \varepsilon \tau \varepsilon \dot{\varepsilon} \omega \rho \alpha$, which Liba Taub translates as "lofty things" in order to capture its inherent vagueness. ${ }^{13} \tau \dot{\alpha} \mu \varepsilon \tau \dot{\varepsilon} \omega \rho \alpha$, from which our term 'meteorology' comes, describes not only what we would think of as most forms of weather (rain, clouds, storms, etc.), but also phenomena like comets and meteors. However, Ptolemy does not use the term at all in the Tetrabiblos; usually, when he is introducing a topic connected with day-to-day weather, he just refers to the 'air' or 'wind' ( $\alpha \dot{n} \rho) \cdot{ }^{14} \mathrm{He}$ occasionally uses the word $x \lambda i \mu \alpha$ for 'climate', and while this refers specifically to latitudes, it also conveys the idea of the characteristic weather in a region. ${ }^{15}$ Throughout this article, I will be considering both the seasons and the climate - that is, the longer-term regional weather characteristics of a specific place - as part of the general category of 'weather' in addition to shorter-term weather events.

Scholars of ancient weather prediction in the Greco-Roman world have proposed several different taxonomies for dividing up and studying methods of predicting the weather. Daryn Lehoux and Liba Taub both distinguish between prediction by weather signs and astrometeorological prediction in the Greek weather tradition. ${ }^{16}$ Prediction by weather signs involves spotting and interpreting signs in the behaviour of the winds, rains, skies, animals, and plants all of which can safely be described as sublunary phenomena. It also makes use of some phenomena - such as comets - which we could consider astronomical but which were considered sublunary in an Aristotelian cosmos. ${ }^{17}$ Some of the signs used in prediction by weather signs were themselves weather phenomena, whereas others were (at first glance) unconnected to weather, such as the behaviour of animals. ${ }^{18}$ Astrometeorological prediction, on the other

\footnotetext{
13 See Liba Taub, Ancient Meteorology (London and New York, 2003), 2.

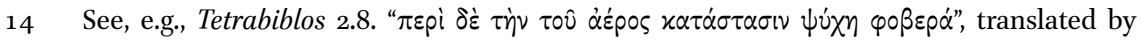
Robbins as: "with regard to weather [Saturn] causes fearful cold." Sometimes in discussion of climate, this is paired with $\chi \alpha \tau \dot{\alpha} \sigma \tau \eta \mu \alpha$ (condition, state) - e.g., Tetrabiblos 2.2. $\tau \dot{0}$

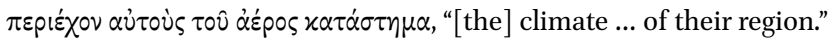

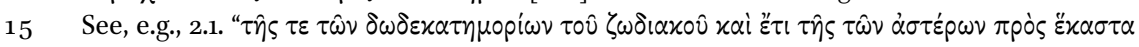

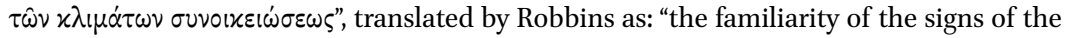
zodiac and also of the stars with the several climes." Unlike the modern term, which can be applied to regions of different sizes, the ancient $x \lambda \mu \mu \dot{\alpha} \tau \alpha$ were specific regions determined by latitude.

16 See, e.g., Taub, Ancient Meteorology, 16; Lehoux, Astronomy, 5 .

17 Comets were thought to occur on the borderline between the sublunary and celestial regions; see Taub, Ancient Meteorology, 108.

18 Modern scientific views may well link certain kinds of animal behaviours to the weather; however, in the modern secular context, unlike the ancient, these are rarely used in a divinatory manner.
} 
hand, involves prediction by the appearance and movement of the stars in their annual cycles, as seen in Ptolemy's Phases. In the case of both types of prediction, the majority of our extant texts take the format of catalogues of signs. ${ }^{19}$ Many of the earlier examples of weather texts tend to mix astrometeorological and weather signs indiscriminately; however, a good number of texts from the Greek world focus exclusively on one or the other. ${ }^{20}$

The ambiguous mix of weather signs and weather prediction by the stars puts the tradition of weather forecasting at the boundary of other divinatory and scientific practices. Its two closest neighbours are divination and astrology, both practices with contested definitions and complex histories. To understand where Ptolemy's discussion of weather fits, I turn first to some other ancient texts which discuss these boundaries.

\section{2 Weather, Divination and Astrology in Cicero and Sextus Empiricus}

The terms 'astrology', 'divination', and 'weather prediction' all refer to groups of methods in the Greco-Roman world for determining the future. Some methods are 'inspired', including those types of divination such as oracles, where a god engages in real-time communication through an inspired human intermediary. ${ }^{21}$ Some are 'inductive'; they are methods of prediction which involve a human practitioner who uses learned skills and sometimes specialist equipment to read 'signs' in the world around them, whether in entrails, animal behaviour, or the stars. ${ }^{22}$ And while it is tempting to divide methods of prediction into 'scientific' and 'religious' prediction, such a categorisation is by no means as clearly demarcated in the ancient context. Ancient writers categorised prediction in a variety of ways, often without clearly linguistically

19 There is also a good deal of archaeological material parapegmata. For an overview of parapegmata, see Lehoux, Astronomy, particularly 3-27.

$20 \quad$ Ibid., $5 \mathrm{ff}$.

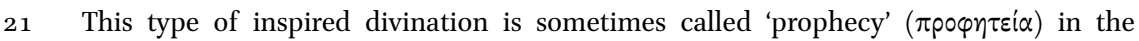
Greco-Roman context and overlaps considerably with Judaeo-Christian and Mesopotamian models of inspired prophecy. For more on 'prophecy' and its terminology, see Martti Nissinen, Ancient Prophecy (Oxford, 2017).

22 For the 'inspired' / 'inductive' terminology, see Pierre Bonnechere, "Divination" in The Blackwell Companion to Greek Religion, ed. Daniel Ogden (Oxford, 2007), 145-16o. See also Sarah Iles Johnston, Ancient Greek Divination (Oxford, 2008), 4ff., who uses the terms 'natural' and 'technical' to mean much the same thing. There is a complex pattern in Greco-Roman religion of which animal behaviours and other natural phenomena can be read as signs; for how signs from augury fit into this pattern, see Lindsay G. Driediger-Murphy, Roman Republican Augury (Oxford, 2019), particularly $56 \mathrm{ff}$. 
demarcating their categories from those of others. It has long been understood that what fits under the terms $\mu \alpha v \tau \varepsilon i \alpha$ or divination (divination) varies from writer to writer. More recently, the ambiguities of what counts as weather prediction have been explored by Lehoux and Taub, among others. In general, scholars have tended to exclude weather prediction from their definitions of divination, considering it instead as a separate scientific form of signinterpretation. ${ }^{23}$ Astrology is often also considered by scholars as a separate, self-contained form of future prediction which has links with divination but which is usually studied as part of the history of science. ${ }^{24}$ These boundaries are necessarily artificial. In this section, I examine two texts which explicitly focus on the taxonomy of different methods of predicting the future, Cicero's On Divination (c. 44 BC) and Sextus Empiricus' Against the Astrologers (late second century AD). These texts categorise weather and astrology differently from Ptolemy, and provide Stoic, Academic, and Sceptic views which all differ slightly in their categorisations; to understand why Ptolemy's categorisation of weather prediction as astrology is so unusual, it is helpful to see how writers both before and after him categorise the same disciplines.

Cicero's On Divination is a helpful introduction to a number of Greco-Roman philosophical positions on various types of prediction and forecasting. ${ }^{25}$ The text takes the form of a dispute between Marcus Cicero and his brother Quintus, and acts as a primer of previous philosophical positions; both speakers make reference throughout to the arguments of a number of named philosophers and schools. ${ }^{26}$ Quintus argues the traditionally Stoic position in favour of divination, while Marcus takes the opposing Academic position. In doing so, they attempt to come to definitions and taxonomies not only of divination, but of a number of other types of prediction, including weather prediction both by signs and the stars.

Quintus begins his defence of divination by quoting some passages about weather from his brother's translation of Aratus' Phaenomena. The passages deal with the prediction of storms by signs, including the behaviour of animals, the state of the sea and the winds. Quintus does not view these as examples of

\footnotetext{
23 Sarah Iles Johnston discusses this boundary in Ancient Greek Divination, $5 \mathrm{ff}$.

24 See, for example, Tamsyn Barton, Ancient Astrology (London, 1994), x-xi on ancient Greek astrology's fit with astronomy and its place within science and medicine.

25 For an introduction to this work, see Wardle's introduction to Cicero, On Divination Book 1 , ed. David Wardle (Oxford, 2006), 8-27.

26 For an interpretation of how to read this interesting text, see Mary Beard, Cicero and Divination: the Formation of a Latin Discourse (Cambridge, 2012); cf. also Malcolm Schofield, Cicero: Political Philosophy (Oxford, 2020).
} 
divination, but as something "similar." 27 He poses a tentative analogy between haruspicy and weather prediction, admitting that he doesn't understand the processes behind either, but trusts the results of both. It seems that he is pointing out that both involve the practice of interpretation of signs in a way that is not necessarily obvious. The rest of his argument further develops a distinction on this point; for him, divination involves divine inspiration, whereas weather prediction and other such skills can be learned. Both, in Quintus' view, are legitimate.

When Cicero responds, he agrees with Quintus that prediction by weather signs is not divination, arguing that divination can only be possible for those events which are not foreseeable by skill or wisdom. ${ }^{28}$ He notes a number of times that crafts that are usually thought of as learned skills rather than divination - for example, the craft of the navigator - involve an awareness of the weather. ${ }^{29}$ The Ciceros take different views on what counts as legitimate. For Marcus, some types of prediction by signs (e.g., weather signs) are a legitimate learned skill, where evidence is used to make deductions through logical reasoning. For him, inspired divination is unrelated and illegitimate. For Quintus, the distinction is less clearly about legitimacy: he endorses both types of prediction, but he cannot clearly explain why.

So far, the Ciceros' discussion has only included weather signs. But later in the work, they explicitly discuss prediction by the stars. Marcus Cicero claims that a number of astronomers reject horoscopic astrology, before summarising a claim (real or putative) made by astrologers that natal horoscopy is valid by analogy with weather prediction:

27 "[...] age, ea quae quamquam ex alio genere sunt tamen divinationi sunt similiora videamus" (So, then, let us consider things which, although they are of another type, are nonetheless similar to divination). On Divination 1.13; translation from Wardle. On the relationship between ecological factors and different divinatory practices and epistemologies in the Roman world, see Dan-el Padilla Peralta, "Ecology, Epistemology, and Divination in Cicero De Divinatione 1.90-94," Arethusa, 51 (2018), 237-267. Padilla Peralta highlights the possibility that Quintus believes that climatological considerations can affect not just which practices are used for future-prediction, but also which outcomes can be generated by those practices, $244 \mathrm{ff}$.

28 "... atqui ne illa quidem divinantis esse dicebas, ventos aut imbres impendentes quibusdam praesentire signis" (And you said that even the foreknowledge of impending storms or rains by means of signs was not divination). On Divination 2.5; translation from Cicero, On Old Age. On Friendship. On Divination, trans. William A. Falconer, Loeb Classical Library 154 (Cambridge, MA, 1923).

29 "Do you think that a prophet will conjecture better whether a storm is at hand than a navigator?" (... num igitur aut, quae tempestas inpendeat vates melius coniciet quam gubernator...?). On Divination 2.5; translation by Falconer. 
Now since, through the procession and retrogression of the stars, the great variety and change of the seasons and of temperature take place, and since the power of the sun produces such results as are before our eyes, they believe that it is not merely probable, but certain, that just as the temperature of the air is regulated by this celestial force, so also children at birth are influenced in soul and body and by this force their minds, manners, disposition, physical condition, career in life and destinies are determined. ${ }^{30}$

Marcus' own opinion is clear: he believes horoscopy to be "all error" and part of divination, which he has already derided as illegitimate. ${ }^{31}$ His objections follow conventional lines: the problem of accurately determining the time of birth, the divergent fates of twins, and conversely, the difficulty of people born at different times sharing the same fate. ${ }^{32}$ But he clearly does accept at least some areas of astrometeorology. What is important to note here is that we have switched from a discussion of signs to a discussion of causes. Marcus' objection is not to the idea that the stars cause effects on earth - in fact, he states quite clearly that the "procession and retrogression of the stars" do cause the change of seasons. Instead, what he objects to is the analogy with horoscopy; he does not think that it follows that because the stars cause the weather, they can cause effects in human lives too. ${ }^{33}$ On this basis, he goes on to claim that the weather itself does not cause effects on human beings:

Therefore, in view of the fact that the sky is sometimes serene and sometimes disturbed by storms, is it a reasonable person's opinion to say that this fact has no natal influence - of course it doesn't - and then assert that a natal influence is exerted by some subtle, imperceptible, even inconceivable force which is due to the condition of the sky, which is in turn due to the action of the moon and stars? ${ }^{34}$

30 "Etenim cum tempestatumque caeli conversiones commutationesque tantae fiant accessu stellarum et recessu, cumque ea vi solis efficiantur, quae videmus, non veri simile solum, sed etiam verum esse censent perinde, utcumque temperatus sit aer, ita pueros orientis animari atque formari, ex eoque ingenia, mores, animum, corpus, actionem vitae, casus cuiusque eventusque fingi." On Divination 2.42.

31 “... omnis error...." On Divination 2.43.

32 For classical uses of these arguments, see Anthony A. Long, "Astrology: Arguments Pro and Contra," in From Epicurus to Epictetus: Studies in Hellenistic and Roman Philosophy, ed. idem (Oxford, 2006), 128-154; see also Tim Hegedus, Ancient Astrology and Early Christianity (New York, 2007), 43ff.

33 Long also discusses this argument as made by Cicero, cf. "Astrology," 134ff.

34 "Haec igitur cum sit tum serenitas, tum perturbatio caeli, estne sanorum hominum hoc ad nascentium ortus pertinere non dicere, quod non certe pertinet, illud nescio quid 
His argument here is that astrologers are inconsistent. They take into account some conditions of the sky (the movements of the moon and stars) but not others (the weather). ${ }^{35}$ From his point of view it is obvious that the weather does not have an effect on the individual, and his aim here is to prove the ridiculousness of astrological theory. But it raises a question for our understanding of Ptolemy's account of weather and causes: does Ptolemy take the weather into account in natal horoscopy?

Before answering this point, I turn to another contrasting example, this time a little later than Ptolemy but closer to his own intellectual background. Sextus Empiricus also writes about the categorisation and epistemology of weather prediction in Book 5 of his Against the Mathematicians, a fragmentary elevenbook polemic against various different intellectual disciplines. ${ }^{36}$ Sextus begins his discussion by trying to identify how astrology relates to other kinds of prediction by the stars:

It lies before us to find out about 'astrology' or the 'mathematical art': [we are not talking about] the complete subject which is made up of arithmetic and geometry ... Nor [are we talking about] the kind of prediction done by Eudoxus and Hipparchus and those like them, which some people call 'astronomy' (this - like agriculture and navigation - is made up of the observation of phenomena from which it is possible to forecast droughts and rainstorms and plagues and earthquakes and other similar changes in the surrounding heavens). Instead, [we are talking about] horoscopy, which the Chaldaeans decorate with holier-sounding names, calling themselves 'mathematicians' and 'astrologers'.... ${ }^{37}$

tenue, quod sentiri nullo modo, intellegi autem vix potest, quae a luna ceterisque sideribus caeli temperatio fiat, dicere ad puerorum ortus pertinere?" On Divination 2.45.

35 How you read this passage depends on how you take Cicero to be using the term caelo ('sky', but also 'heavens', with no technical distinction between the two implied). The most likely reading is that he is making a straightforward polemical point: if you look up at the heavens / sky and there are storms, you don't take that into account in an astrological prediction, whereas you do take into account the movement of planets and stars [even though those are further away].

36 For an introduction to Sextus Empiricus and Pyrrhonian scepticism, see Julia Annas and Jonathan Barnes, The Modes of Scepticism (Cambridge, 1985).

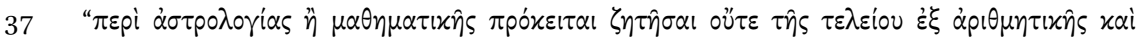

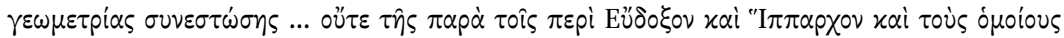

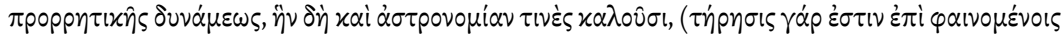

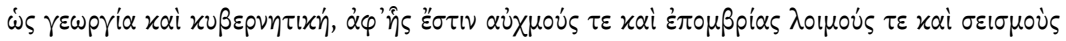

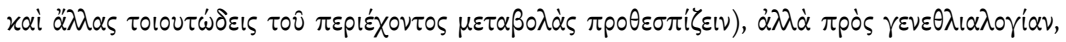

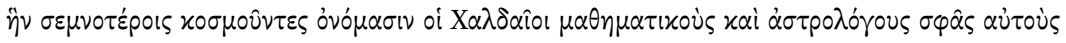

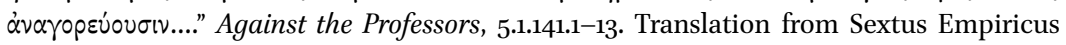


The categorisations used here are slightly different from those in $O n$ Divination; the rhetorical and intellectual purposes of the texts are different. While Cicero was arguing that weather prediction was a learned skill, and Quintus was arguing that it was not divination but something similar (i.e., both men were drawing dichotomies between 'divination' and 'not divination'), Sextus discusses the different types of prediction using the stars. $\mathrm{He}$ starts, therefore, not from a consideration of the nature of the knowledge, but its source. Yet the picture Sextus sets up is clear. He defines the object of his derision - astrology - negatively by establishing, first of all, that it is not mathematics (as we understand mathematics), and then that it is not astronomy. Forecasting from the stars on the basis of astronomy is fine - and in Sextus' view it is possible to forecast "droughts and rainstorms, plagues and earthquakes" from the stars. In highlighting this point, Sextus compares astronomy to the practical crafts of agriculture and navigation; perhaps not coincidentally, these are the two practical crafts that have most to benefit from accurate weather prediction, also noted by Cicero as the crafts which demonstrate general rules for predicting future patterns. However, definitionally, for Sextus, astrology is natal horoscopy - which takes the stars not just as legitimate and legible signs, but as claims that they can produce effects in human lives.

While the Ciceros and Sextus use different examples in their discussions of weather prediction, in both texts it is taken as self-evident that weather prediction is (a) possible, and (b) legitimate. In both cases, weather prediction is used apophatically in setting up a definition. In the first case, it is an example of a specific technical skill that is 'not divination' and it is used to delimit divination. But it is clearly not astrology either. In Sextus' case, weather prediction is an example of what is 'not astrology' in his dichotomy, used to delimit horoscopic astrology. But they diverge in how they see signs and causes. For Cicero, some kinds of prediction by signs are possible and legitimate, including prediction by weather signs and the stars. But Cicero is also clear that the stars are the cause of weather as well signs of it. For Sextus Empiricus, on the other hand, prediction using the stars is acceptable when it treats the stars as signs: for example, we can predict where the stars will move next (astronomy), and what these movements might indicate by means of observation for weather. Astrology, in his view, is not legitimate because it treats the stars as causes. If we turn to Ptolemy's Tetrabiblos, we will see that he takes quite a different approach to the relationships between stars, weather, and prediction.

Vol. IV, Against Professors, trans. Robert Gregg Bury, Loeb Classical Library 382 (Cambridge, MA, 1949). 
Early on in the Tetrabiblos, Ptolemy makes three definitional statements which are important for our purposes. ${ }^{38}$ The first appears at the start (Tetrabiblos 1.1.1), where Ptolemy declares that there are two types of prediction as regards the stars. First, there is the prediction of their movements (what we would call 'astronomy'), and secondly, the prediction of their effects on earth (what we would call 'astrology'). The first type, astronomy, he deals with in the Almagest. The Tetrabiblos is the treatment of the second type, astrology. The rest of Book 1 of the Tetrabiblos explains in detail astrology's underlying physical and theoretical structure, including first-principles definitions of the nature and characteristics of the planets, fixed stars, signs of the zodiac, and their relations to one another.

Ptolemy's second major definition comes at the start of Book 2, where he divides astrology into two types. ${ }^{39}$ The first type is "general" ( $\left.\kappa \alpha \theta 0 \lambda \iota x o ́ v\right)$ astrology, and Ptolemy notes that it is "more universal" ( $\gamma \varepsilon v \iota \varkappa \omega \tau \varepsilon \dot{\varepsilon} \rho \nu)$ than the second. General astrology makes predictions about "whole peoples, countries,

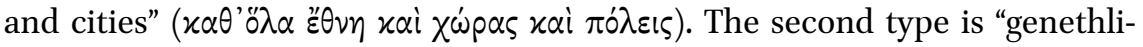
alogical" ( $\gamma \varepsilon v \varepsilon \theta \lambda \iota \alpha \lambda \circ \gamma(x o ́ v)$ astrology, more commonly known in modern terminology as horoscopic astrology - specifically, natal horoscopy (i.e., the casting of a horoscope of individuals based on their time of birth) ${ }^{40}$ Ptolemy does not explain what is included in this second type, which may suggest that his readers are expected to be more familiar with natal horoscopy than with general astrology. As well as drawing this distinction, Ptolemy justifies his decision to treat general astrology first, which he does in the rest of Book 2:

I think it is appropriate to treat first the general division, because such matters are naturally influenced by greater and more powerful causes than particular events. And since weaker natures always yield to the stronger, and the particular falls under the general, it would be entirely

38 For more on Ptolemy's preface to the Tetrabiblos and how it relates to the preface of the Almagest, see Jaap Mansfeld, Prolegomena Mathematica (Leiden, 1998), ch. 9: "Ptolemy's Prefaces," 66-75, esp. 71ff.; Mansfeld does not discuss the Phases.

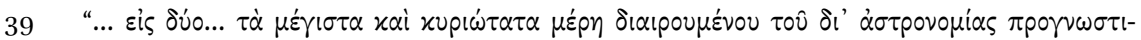
к०ט...." "(Prognostication by means of astronomy is divided into two large and principal types)." Tetrabiblos 2.1.2, H88 (page references following 'H' are to the Hübner edition, Apotelesmatika); translation by Robbins.

40 The two terms are not exactly equivalent: 'horoscopic' derives from the term for the rising

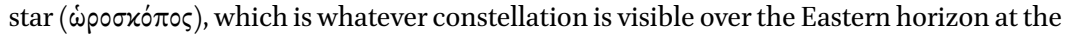
time of the person's birth. 'Genethlialogical' is derived instead from the term for birth. 
necessary for those who intend to enquire about a single individual to have already long before understood the more general considerations. ${ }^{41}$

This passage is sometimes read as inscribing a strict division between general and natal astrology. It is clear that Ptolemy is intending here to draw a conceptual difference between the two types. However, the language - particularly the phrase "the particular falls under the general" (i $\pi 0 \pi i \pi \tau 0 v \sigma \hat{\omega} \nu$... $\tau \omega \nu$ x $\alpha \tau \dot{\alpha}$

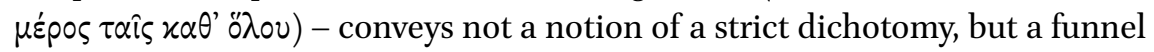
structure in which the astrologer is encouraged to begin with general considerations in order to set up a backdrop before moving on to natal horoscopy. Once Ptolemy has established the distinction between horoscopic and general astrology, he makes one more definitional point, this time within general astrology. He distinguishes between events that are one-off and infrequent (war, famine, pestilence, floods), and those which are annual or frequent (seasons, temperatures, storms, winds, the flourishing or failure of crops). As we can see from the way this is divided, events that we would think of as weather are represented in both categories.

Tetrabiblos 2 includes three sections which involve weather prediction. ${ }^{42}$ The first of these discusses the climate in different regions and its connection to the stars as well as the effects of climatological considerations on individual horoscopy. The second is on predicting one-off general events, including weather events. The third discusses methods for predicting fluctuations in seasonal weather. In each of these cases, weather is the key to understanding how the relationship between general and horoscopic astrology works: in the case of climate, Ptolemy (indirectly) answers the same criticism expressed by Cicero: that astrologers do not take into account weather conditions for natal horoscopy; Ptolemy shows that, in fact, they do. In the second and third sections, he uses methods more usually associated with natal astrology (such as casting horoscopes) to make weather predictions. Taub has argued that Ptolemy's discussions of weather in the Tetrabiblos indicate his belief that only specialist astronomers can make the 'best' weather predictions. ${ }^{43}$ I believe that Taub is right, but I would go further. The way in which Ptolemy mixes weather throughout his discussions of general and horoscopic astrology shows two

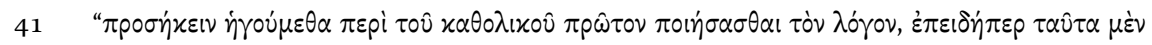

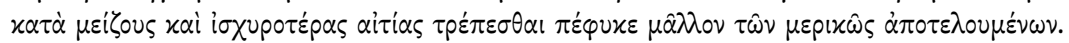

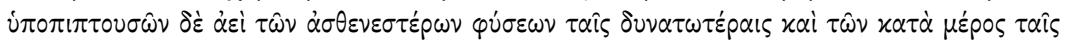

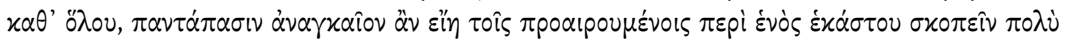

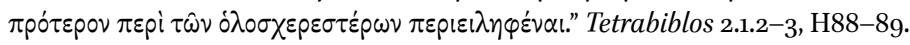

42 Ibid., 2.2-4, H9o-125; 2.5-11, H124-15o; 2.12, H154-158.

43 Taub, Ancient Meteorology, 34ff. 
things: first, that for Ptolemy, weather prediction is itself a form of astrology, not a separate practice informed by astrology. Secondly, Ptolemy's treatment of weather demonstrates that general and horoscopic astrology are not substantially different in their methods and aims, but instead represent a spectrum of astrological enquiry from the broadest possible objects (whole regions, seasons, reigns of kings, spans of time, events over many months affecting many people) to the narrowest (weather on individual days, the lives of individual human beings).

\subsection{Climate}

One of the perennial problems of astrology was the question of regional difference. It was a matter of undeniable experience that people living in different countries and cities had particular cultural practices and characteristics which were regionally specific and shaped their experiences of the world. ${ }^{44}$ Critics of astrology used this fact to put forward arguments about the divergent fates of individuals from different cultures: for example, two people born at exactly the same time, one in Alexandria and one in Roman Britain, would live very different lives on the basis of geography alone. ${ }^{45}$ Ptolemy responds to this criticism with a long passage which covers the relationships between zodiac signs and regions of the earth. The main theoretical basis for this is the notion of the 'triangles' or 'triplicities', a widespread astrological theory that Ptolemy makes much use of in the Tetrabiblos. The signs of the zodiac are divided into four 'triangles' (fiery; earthy; airy; watery) and the planets and signs divided between them. In the Ptolemaic system, the planets and signs have characteristic qualities based on Aristotelian four-element theory: for example, some are hot and some cold, some wet and some dry, and so on. ${ }^{46}$ In Tetrabiblos 2.2-4, Ptolemy

44 This fact was often framed in ethnically prejudicial language in the ancient world; in particular, other peoples' sexual practices are the subject of frequent and prurient speculation. Persians were often particularly viciously stereotyped in Greek texts. However, unlike modern racial stereotyping, few of the common stereotypes in the astrological lore are based on skin colour - which is observed as a physical difference but treated in relatively neutral language. See Hegedus, Ancient Astrology and Early Christianity, 179ff; Alexander Boxer, A Scheme of Heaven: Astrology and the Birth of Science (New York, 2020), $112-118$.

45 Versions of this criticism come to be grouped under the name vó $\mu \mu \alpha \beta \alpha \rho \beta \alpha \rho$ i $\alpha$ (barbarian customs); see Hegedus, Ancient Astrology, 91ff.; see also Long, "Astrology."

46 For an overview of how Ptolemy's system works, see Feke, Ptolemy's Philosophy, $176 \mathrm{ff}$. For Aristotle's physical theory, including his element theory, see Eric Lewis, "Aristotle's Physical Theory," ch. 11 in The Cambridge History of Science, ed. Adrian Jones and Liba Taub (Cambridge, 2018), 196-214. 
maps these triangles onto the earth, and from there uses the characteristics of the signs and planets to explain climatological and human characteristics.

Ptolemy relates human characteristics directly to climate. For example, according to Ptolemy, the Scythians, who live in the Northern reaches, are likely to be cold of temperament because of their relation to the colder signs, but also because of their exposure to cold weather. He also asserts that the physical characteristics of human beings can come about as a result of the weather associated with their geographical position. For example, Scythians are lightskinned because they live in cold and moist places. ${ }^{47}$ In Tetrabiblos 2.3, Ptolemy makes a comment that is pertinent for answering Cicero's earlier objection that astrologers do not take weather conditions into account for natal horoscopy:

One would discover special traits in each [person] arising from the natural familiarity of their particular climates with the stars in the signs of the zodiac. These traits, too, would be found generally present, but not in every individual. We must, then, deal with the subject summarily, in so far as it might be of use for the purpose of particular investigations. ${ }^{48}$

This is an explicit statement that climate conditions play a role in horoscopic astrology: the climate of each place has its own astrological characteristics and some of those - in different manifestations - are inscribed in people born there. However, as Ptolemy notes, this is not straightforward: the traits are found across the population as a whole, rather than on a person-by-person basis. While it is not stated, Ptolemy seems here to be saying that these characteristics can be found regardless of whether they are present specifically in the person's natal horoscope: they make up part of the backdrop. In this way,

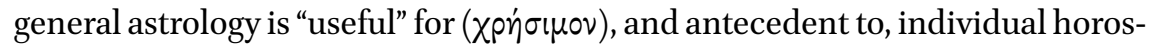
copy. This material on climate establishes that horoscopy and general astrology are linked, and that weather (in the form of climate) is one of the links. But if we move on to Ptolemy's method for predicting one-off general events, we see an even closer link with natal horoscopy: the method he proposes involves making some direct deductions from astronomical and weather phenomena, but also casting horoscopes of these phenomena.

47 Tetrabiblos 2.2.4-5, H91-92.

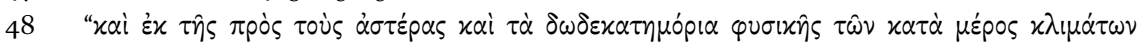

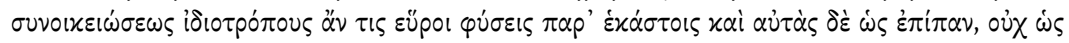

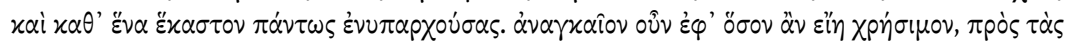

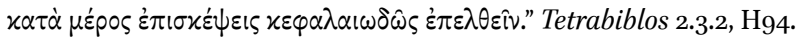




\subsection{Predicting One-Off General Events}

To predict one-off general events, Ptolemy gives a detailed and complex method, which I will briefly outline. There are four steps to the method. First, to find out the location of the event, you track any of the following phenomena: eclipses (solar or lunar); stations of Saturn, Jupiter or Mars (that is, points where they are entering or leaving retrogression); comets; haloes; and atmospheric signs. You only take into account those locations where the phenomena are visible; you find out what sign of the zodiac the phenomenon takes place in, and can then find out whether any locations have a link with that sign, either - as in the previous section - by their climate, or if there are particular elements in their foundation horoscope, or in their ruler's horoscope, that correspond with the sign. This determines which locations the event may happen in. Secondly, to find out the time of the event and how long it will last, you write down the time of the phenomenon in the location in question. Next you find out how long the phenomenon is visible in equinoctial hours, and you can then convert this, using a formula that Ptolemy gives, into how long the event will last in months or years. ${ }^{49}$ To find out when the event will begin, you look at where in the sky the phenomenon appears: if near the eastern horizon it will happen within four months; if near mid-heaven, it will happen between four and eight months from the eclipse; if near the western horizon, it will happen between eight and twelve months from the eclipse.

Thirdly, to find out what sort of event it will be, and who or what will be affected by it, you look at the sign in which the phenomenon occurs and check the triangle of that sign and of the sign of the angle preceding the phenomenon. ${ }^{50}$ Fourth and finally, to find out whether the event will be beneficial or detrimental you take the horoscope of the phenomenon, and find out, as in a horoscope, which planets have effects through their aspects. ${ }^{51}$ In these

49 'Equinoctial hours' are how long it takes for 15 degrees of the equator to move past the horizon, i.e., an hour. 'Totality' in solar eclipses lasts from a few seconds to around 8 minutes; in their case, Ptolemy says that the event will last as many years as the number of equinoctial hours' duration of the eclipse. So, an eclipse lasting 5 minutes (1/20th equinoctial hour) signifies an event lasting around 18 days. In the case of lunar eclipses, where totality lasts up to 2 hours, the event will last as many months as the number of equinoctial hours in the duration of the eclipse. So, an eclipse lasting 75 minutes (1 1 1/4 equinoctial hours) signifies an event lasting a month and a quarter. Both methods therefore generally give short- to mid-range forecasts of events lasting from between around a day to around two months.

50 The 'angle' in astrology means one of four houses: the ascendant (i.e., where the horoscope is), midheaven, descendant, or the imum caeli; see Chris Brennan, Hellenistic Astrology (Denver, CO, 2017), 319ff.

$5^{1} \quad$ Tetrabiblos 2.8 . 
last two steps, Ptolemy gives a number of examples. Many of them concern the weather. For example, he explains that the terrestrial signs signify different weather conditions, including earthquakes and rain, or that the solstitial and equinoctial signs tend to have significance for the condition of the air. ${ }^{52}$ For the final step, where the effects of the planets are mentioned, Ptolemy gives a list for each planet. Each list contains some information about the planet's effects on people and livestock, but also on weather. For example, Saturn is said to cause "cold, freezing, misty and pestilential winds", Jupiter to "make the condition of the air temperate" and Venus to cause "generous showers of fertilising waters." ${ }^{53}$

This method shows the flexibility of Ptolemy's system. Some of the general events that Ptolemy seems to have in mind are what we would think of as weather-related phenomena: floods, storms, earthquakes, droughts. Others are outside of the realm of weather, with the most obvious example being wars. Some are composite: famine, for example is a result of drought, but is also a social phenomenon. There is no clear distinction drawn between 'weather' and 'non-weather' events; they form a continuous category of general events in Ptolemy's thinking - that is to say, prediction of major weather events is fully integrated into general astrology. Ptolemy's methods correspond exactly to what he specifies in the prologue of the Phases: that in predicting the weather one should observe and take into account the sun and moon (as in eclipses), and the planets and their angles. They also show the flexibility of his general / horoscopic distinction particularly when it comes to weather. Although the method is for predicting 'general' events, some of the methods used are

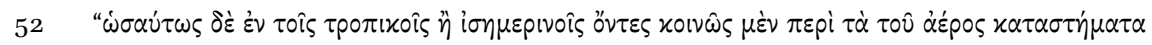

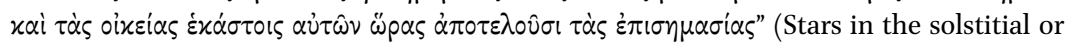
equinoctial signs [i.e., Cancer, Capricorn, Aries, Libra] have significance in general for the conditions of the air and the seasons related to each of these signs). Tetrabiblos 2.8.10, $\mathrm{H} 132$.

53 Saturn: "With regard to airs / winds, he causes fearful cold, freezing, misty and pestilential winds, corruption of the air, clouds, and gloom ... multitudes of snowstorms, not beneficial but destructive, from which are produced the reptiles harmful to man." Tetrabiblos 2.9.5-8; Jupiter: "He makes the condition of the air temperate and healthful, windy, moist, and favourable to the growth of what the earth bears." Tetrabiblos 2.9.9-10; Mars: "He causes hot weather, warm, pestilential, and withering winds, loosing of lightning and hurricanes, droughts." Tetrabiblos 2.9.11-13; Venus: "[She causes] temperateness, settled conditions of moist and very nourishing winds, of good air ... generous showers of fertilising waters." Tetrabiblos 2.9.14-15; Mercury: "[He causes] irregular, fierce and changeable winds, and, as might be expected, thunder, hurricanes, chasms in the earth, earthquakes and lightnings." Tetrabiblos 2.9.16-18. 
horoscopic: for example, in the final step a horoscope of the event itself is cast as if the beginning of the event were a birth.

\subsection{Fluctuations in Seasonal Weather}

The next section provides methods for predicting seasonal and recurrent weather at various different timescales. ${ }^{54}$ In this section, Ptolemy deals specifically with the weather, not with other categories of general events. First, and most straightforwardly, Ptolemy provides a list of the general weather conditions for each sign - that is, each month; most of these are essentially the same as seasonal weather patterns in the Mediterranean now. ${ }^{55} \mathrm{He}$ specifies how the beginning, middle, and end of each month is characterised by certain weather, and gives northerly and southerly variations for the various weather types. Less obviously, as we saw in the prediction of general events, the planets also have their own characteristic weather. ${ }^{56}$ In the one-off general event predictions, the effects of the planets manifested themselves through their roles in an eclipse's horoscope. But in methods for the prediction of seasonal weather, the planets' effects also play a role.

To explain these methods, Ptolemy goes through several different timescales for predicting blocks of weather. The longest window he gives is a threemonth period, i.e., roughly the length of a whole season. Ptolemy's method here is similar to general event prediction with eclipses:

We observe the new moons or full moons which most nearly precede the solstitial and equinoctial signs, and, as the degree of the new moon or of the full moon may fall in each latitude investigated, we dispose the angles as in a nativity. ${ }^{57}$

Essentially, Ptolemy states here that one may predict the weather for threemonth periods following either an equinoctial or a solstitial sign (Aries, Cancer, Libra, and Capricorn) by taking a horoscope of the moon. The next

54 Tetrabiblos 2.10-14, H145-164.

55 These are Aries (thunder, hail); Taurus (somewhat hot); Gemini (equable temperature); Cancer (fair, warm weather); Leo (hot and stifling); Virgo (moist and stormy); Libra (changeable and variable); Scorpio (thunder and fiery); Sagittarius (windy); Capricorn (moist); Aquarius (cold and watery); Pisces (cold and windy). Tetrabiblos 2.12.2-8, H151-154.

56 Cf. Tetrabiblos 2.8.5ff.

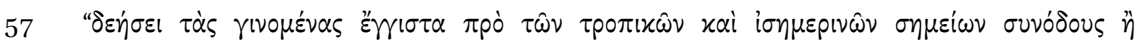

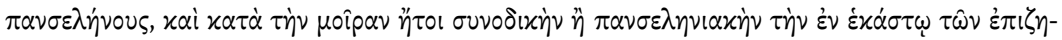

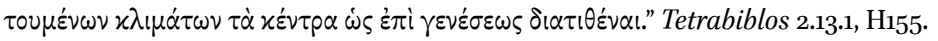


time-window Ptolemy deals with is month-by-month predictions. This also involves horoscopes of the new moon, but in this case closest to the beginning of each sign. The final, smallest time-window is day-to-day fluctuations. For this, Ptolemy advocates tracking the position of the luminaries - that is, the sun and moon - as they pass, taking into account the times when the new moons and half-moons occur. He also suggests taking into account the aspects of the sun and moon to the planets.

Throughout these sections on weather, Ptolemy discusses topics spanning all of general astrology. His methods for predicting the weather range from weather signs to techniques usually associated with natal horoscopy; he sometimes talks about weather phenomena as the effects of the stars, and at other times as signs in themselves. In the prologue of the Phases, Ptolemy specifies that one should have a knowledge of causes as well as signs. In what remains of the article, I want to explore a little further what he might mean by this, and why his treatment of weather prediction as astrology addresses this issue.

\section{Weather and Astral Causation}

A long-running debate in a number of Greco-Roman texts on astrology concerns the difference between signs and causes: in short, do the stars themselves cause effects on earth or are they just to be read as signs (which don't, per se, provide any information about the causes of the effects on earth)? The different philosophical schools took a variety of positions on this issue: from the pre-Socratics onwards the association between souls and the heavenly bodies played a part in a number of theories of astral influence or causation.58 Additionally, the longstanding association between the planets and the gods also meant that the language of action and cause was frequently used for planets in ways that straddle the literal and the metaphorical. ${ }^{59}$ Stoic views on the interconnectedness of the heavens and the earth were particularly influential. ${ }^{60}$

$5^{8}$ See, e.g., Plato, Timaeus, $41 \mathrm{~d} 8 \mathrm{ff}$.

59 See, e.g., Vettius Valens, Anthologies, 1.1. Cf. also Auguste Bouché-Leclercq, L'Astrologie grecque (Paris, 1899), 93ff; Barton, Ancient Astrology, 111f.

6o Stoic theories of causation are notoriously difficult; see Susanne Bobzien, "Chrysippus' Theory of Causes," in Topics in Stoic Philosophy, ed. Katarina Ierodiakonou (Oxford, 1999), 196-242. For Stoic cosmology, see Michael J. White, "Stoic Natural Philosophy (Physics and Cosmology)," in The Cambridge Companion to the Stoics, ed. Brad Inwood (Cambridge, 2003), 124-152. 
By the second century AD, the signs / causes debate was established enough to become a philosophical set-piece. ${ }^{61}$

In most other forms of divination, the phenomena under study were not usually claimed to be causes themselves but a series of signs which provided evidence for the conclusions reached by the divinatory practice. ${ }^{62}$ Sextus Empiricus provides a Stoic definition for 'signs': that signs must be epistemically antecedent to the thing they are signifying, and therefore revelatory of that thing. ${ }^{63}$ In Aristotle, the distinction can be framed in terms of theory of knowledge: scientific knowledge involves understanding not just that something is, but why it is - i.e., understanding of the causes. ${ }^{64}$ While signs can act as evidence and can be used in logically valid inferences, they do not provide a full explanation of the phenomena. ${ }^{65}$ As Feke has argued, Ptolemy's philosophical influences were eclectic, and he drew on a range of ideas including Aristotelian and Stoic doctrines. His reading of the term 'sign' would certainly have been influenced by both Aristotelian and Stoic discussions. ${ }^{66}$

In the case of the weather, it seems clear from Ptolemy's discussion of the planets that he believes the planets not merely to be signs but causes of certain conditions - including not just human characteristics or types but also general events, including weather. ${ }^{67}$ This may also apply to the fixed stars: it is not

61 See the lengthy discussion of the stars as signs vs. causes in Plotinus, Enneads, 2.3, and in Origen, Philocalia 23: both conclude that the stars are not causes but a system of heavenly writing; cf. Claire Hall, "Origen and Astrology," in Studia Patristica Vol C, ed. Hugh A.G. Houghton, Megan L. Davies and Markus Vinzent (Leuven, 2020), 113-122. On Aratus and heavenly writing, see also Katharina Volk, "Letters in the Sky: Reading the Signs in Aratus' Phaenomena," The American Journal of Philology, 133 (2012), 209-240.

62 Augustine gives the following definition: "a sign is something that brings it about by itself that something apart from the impression it makes on the senses comes to mind"; see $O n$ Christian Doctrine 2.1.1, trans. Roger P.H. Green in De doctrina Christiana (Oxford, 1995).

63 Sextus Empiricus, Outlines of Pyrrhonism 2.104; idem, Against the Mathematicians 8.245. For an explanation of the Sceptic view of signs which Sextus puts forward, see Richard Bett, How to Be a Pyrrhonist (Cambridge, 2019), ch. 4: "The Sign in the Pyrrhonian Tradition," 69-88.

64 Aristotle explains versions of this view in various places, including most clearly in Posterior Analytics 1.2; see Hermann Weidemann, "Aristotle on Inferences from Signs," Phronesis, 34 (1989), 343-351.

65 For more on ancient definitions of signs, see James Allen, Inference from Signs: Ancient Debates about the Nature of Evidence (Oxford, 2001).

66 See Feke, Ptolemy's Philosophy, 1-25.

67 For a modern person, this makes intuitive sense in the case of the sun but not the other planets, although strictly speaking, the sun does not actually cause variation in temperature or weather; while the sun causes the earth to be heated, any variation (and therefore 'weather' as we think of it) is due to the movement and tilt of the earth. While this point 
clear, for example, whether Ptolemy would claim that Pisces causes cold and windy weather, but it is not prima facie implausible. More difficult are those phenomena which can be read as both signs and causes. As we saw above, Ptolemy advocates the use of horoscopic methods for lunar phenomena, including taking horoscopes of eclipses and new moons to predict the weather. In these cases, there is a complex relationship between cause and sign, with several different configurations of causes and signs. First, the moon is, as a planet, obviously itself a cause - both in astrology broadly but also as regards the weather. However, when eclipses and new moons are used as anchors to make place-sensitive or time-sensitive predictions, they are functioning not as causes but as signs. When these lunar phenomena are treated as the native of a horoscope, then the moon and the other planets are being identified as causes at the same time as the moon functions as a sign. For example, the new moon can act as a sign and a native for a horoscope. However, working out the aspects of planets then involves treating the moon as a cause.

To see this more clearly, we can turn to another section of the Tetrabiblos where Ptolemy treats lunar phenomena. Alongside using lunar phenomena as natives for horoscopy, Ptolemy also advocates making observations of various physical aspects of the phenomena, including colour and haloes, in order to map them to physical conditions on earth. For example, "For if [haloes around eclipses] appear black or livid they signify the effects which were mentioned in connection with Saturn's nature." 68

In this example, signs to do with the moon and sun are an indication of Saturn causing something - i.e., bodies which we think of as causal agents (planets) can also be signs for other causal agents (other planets). Throughout the Tetrabiblos and the Phases, Ptolemy shows a complex appreciation for the interplay of signs and causes in weather prediction. In the same way that weather prediction shows that general astrology can be the backdrop for horoscopic astrology without inscribing a strict distinction between the two, weather prediction shows us also the interconnectedness of signs and causes in Ptolemy's thinking.

reveals something about how we talk about causes, the overall thrust of the argument still stands: in modern scientific thought, the link between the sun and moon and weather is direct, whereas the link between other planets or other stars is not. 


\section{Conclusion}

The Ciceros and Sextus accepted astrometeorology in the form of the traditional content of parapegmata, i.e., lists of signs which posited no particular causal relationship between the stars and the weather. While the Phases seems at first glance to imply the same position in Ptolemy, when we look to the Tetrabiblos, we find the weather plays a much more anarchic role. Through examining the passages of the Tetrabiblos that relate to weather, I have tried to argue that for Ptolemy it is clear not just that that the stars cause the weather but that their relationships to one another and to weather phenomena are also causes for other sublunary effects (including human characteristics). Sometimes - as in the case of climate - even weather phenomena themselves can be causes. In this model, weather prediction is a form of astrology which uses methods spanning from the general to the horoscopic.

\section{Acknowledgements}

I am grateful to Liam Shaw, to the anonymous reviewers of Early Science and Medicine, and to Christoph Lüthy for helpful comments on this article. 